\title{
Lessons from the past
}

\section{F. Basile ${ }^{1} \cdot$ Fulvio Calise $^{2}$}

Published online: 3 September 2020

(c) Italian Society of Surgery (SIC) 2020

\section{Dear Editors}

These are times of sorrow for the entire world. The COVID-19 outbreak has upset all our certainties, redirected the role of our health facilities forcing them to a permanent alert for an unknown future. Italy has been the first western country to face the pandemic and develop strategies followed by many other countries.

UPDATES in Surgery has decided to open this issue with a paper from the University of Milan that tells us what happened a century ago in another dramatic outbreak: World War 1.

Surgeons from the Italian Society of Surgeons, celebrating this year its 122nd anniversary, took the lead to develop and organize Mobile Surgical Hospitals behind the frontlines. They organized crash courses attended by hundreds of volunteers of any disciplines, wrote pocket manuals, visited French and German medical installations, and carried out an impressive (at the time) fundraising campaign to prepare the medical community to face the imminent war. Remarkable clinical outcomes of this policy for wounded patients are shown. Finally, at the outbreak of the Spanish flu, the Mobile Hospitals hosted soldiers with Spanish fever.
Nowadays, in a much different context, surgeons have carried on with their personal battle just like their colleagues a hundred years ago, for the sake of their patients. History repeats itself.

\section{Compliance with ethical standards}

Disclosure of potential conflicts of interest The authors declare that they have no conflict of interest.

Research involving human participants and/or animals This article does not contain any studies with human participants or animals performed by any of the authors.

Informed consent For this type of study formal consent is not required.

Publisher's Note Springer Nature remains neutral with regard to jurisdictional claims in published maps and institutional affiliations.
Fulvio Calise

fulvio.calise@libero.it

F. Basile

fbasile@unict.it

1 Division of General and Oncologic Surgery, Surgical Department, Azienda Ospedaliero Universitaria "Policlinico

G. Rodolico- San Marco", Catania, Italy

2 Department of General Surgery, Center for Hepatobiliary and Pancreatic Surgery, Pineta Grande Hospital,

Castel Volturno, CE, Italy 